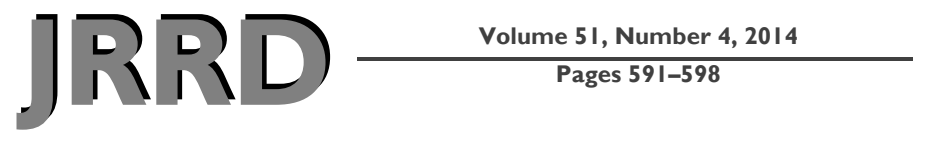

\title{
Reliability, agreement, and validity of digital weighing scale with MatScan in limb load measurement
}

\author{
Senthil N. S. Kumar, MSc; ${ }^{1}$ Baharudin Omar, PhD; ${ }^{1}$ Ohnmar Htwe, MD; ${ }^{2}$ Leonard H. Joseph, MsPT; ${ }^{1^{*}}$ \\ Jagannathan Krishnan, PhD; ${ }^{3}$ Ali Jafarzedah Esfehani, MD; ${ }^{1}$ Lee L. Min, BScPT (Hons) ${ }^{1}$ \\ ${ }^{1}$ Faculty of Health Sciences, Universiti Kebangsaan Malaysia, Kuala Lumpur, Malaysia; ${ }^{2}$ Department of Orthopedics \\ and Traumatology, Faculty of Medicine, Universiti Kebangsaan Malaysia Medical Centre, Kuala Lumpur, Malaysia; \\ ${ }^{3}$ Faculty of Chemical Engineering, MARA University of Technology, Shah Alam, Malaysia
}

\begin{abstract}
Limb loading measurements serve as an objective evaluation of asymmetrical weight bearing in the lower limb. Digital weighing scales (DWSs) could be used in clinical settings for measurement of static limb loading. However, ambiguity exists whether limb loading measurements of DWSs are comparable with a standard tool such as MatScan. A crosssectional study composed of 33 nondisabled participants was conducted to investigate the reliability, agreement, and validity of DWSs with MatScan in static standing. Amounts of weight distribution and plantar pressure on the individual lower limb were measured using two DWSs (A, B) and MatScan during eyes open (EO) and eyes closed (EC) conditions. The results showed that intra- and interrater reliability $(3,1)$ were excellent (0.94-0.97) within and between DWS A and B. Bland-Altman plot revealed good agreement between DWS and MatScan in EO and EC conditions. The area under the receiver operating characteristic curve was significant and identified as $0.68(p=$ 0.01 ). The measurements obtained with DWSs are valid and in agreement with MatScan measurements. Hence, DWSs could be used interchangeably with MatScan and could provide clinicians an objective measurement of limb loading suitable for clinical settings.
\end{abstract}

Key words: agreement, asymmetry, digital weighing scale, limb loading, measurement, plantar pressure distribution, rehabilitation, reliability, validity, weight distribution.

\section{INTRODUCTION}

Standing is an essential fundamental position to carry out functional activities of daily living [1]. The ability to maintain the body in equilibrium during standing is influenced by factors such as visual input and lower-limb weight distribution [2-4]. The presence of visual input improves postural control in standing [1]. On the other hand, eyes closed (EC) during standing produces a greater body sway, resulting in postural instability leading to asymmetrical limb loading [3,5]. Limb loading distribution is said to be symmetrical when both lower limbs load equally. Functional activities such as standing and

\footnotetext{
Abbreviations: DWS $=$ digital weighing scale, $\mathrm{EC}=$ eyes closed, EO $=$ eyes open, ICC $=$ intraclass correlation coefficient, LLA = limb loading asymmetry, LoA = limits of agreement, $\mathrm{PPD}=$ percentage of pressure distribution, $\mathrm{PWD}=$ percentage of weight distribution, $\mathrm{ROC}=$ receiver operating characteristic, $\mathrm{SD}=$ standard deviation, $\mathrm{SI}$ = symmetry index.

*Address all correspondence to Leonard H. Joseph, MsPT; Physiotherapy Program, School of Rehabilitation Sciences, Faculty of Health Sciences, Universiti Kebangsaan Malaysia, 5th Floor, Bangunan Yayasan Selangor, Jalan Raja Muda Abdul Aziz, 50300, Kuala Lumpur, Malaysia; +60 19-6781-935. Email: leonardjoseph85@gmail.com

http://dx.doi.org/10.1682/JRRD.2013.07.0166
} 
walking are said to be energy efficient when both lower limbs behave symmetrical in loading [1,7]. However, unequal limb loading in the long term may lead to complications such as osteopenia, cartilage destruction, and joint degeneration [6-7]. Hence, in clinical practice, quantification of weight distribution on lower limbs is crucial in rehabilitation of patients with lower-limb pathologies such as lower-limb fractures, amputations, joint replacements, and stroke [6].

Limb loading can be quantified by digital weighing scales (DWSs), biofeedback systems, MatScan (Tekscan Inc; South Boston, Massachusetts), ambulatory devices, and force platforms [6]. Biofeedback systems, MatScan, ambulatory devices, and force platforms provide more reliable and accurate data than DWSs [6]. However, the aforementioned devices are more expensive, require trained personnel, and are not available in common clinical practice $[6,8]$. Hence, they are seldom in use to measure limb load asymmetry (LLA). Conversely, using two DWSs is the conventional method used by practitioners to measure asymmetry of weight bearing on lower limbs [9]. DWSs give an instant quantitative reading of weight in kilograms [10] with a precision up to two decimal points $[6,11]$. DWSs are portable, cheap, less time consuming, easily accessible, light, and small [6]. DWSs do not require additional training for clinicians and patients and have good accuracy in static weight bearing measurements [6].

Despite the usefulness of DWSs, their reliability and validity have not been tested [12]. Reliability is defined as consistency of output yielded on repetitive measurements using a DWS with clinically acceptable measurement [13]. Agreement concerns the absolute measurement error, which addresses how close the measurements obtained from equipments are to one another [14]. It refers to the extent to which measurements between DWS and MatScan are identical. Validity concerns the extent to which equipment measures what it is intended to measure [14]. It refers to the degree to which limb loading measurement of a DWS correlates with the standard measurement tool. In clinical practice, force platform [6] and MatScan [15] are considered the standard tools for limb load assessment. Hence, there would be an interest in knowing whether DWSs are in agreement or could be used interchangeably with the aforementioned tools to measure LLA [16]. The aim of this study was to investigate the reliability, agreement, and validity of DWSs with MatScan to measure LLA among the nondisabled population during eyes open (EO) and EC conditions. DWSs are a commonly available tool, portable, cost-effective, and need less skill to maneuver; hence, if they are proven to be valid and reliable they could provide practitioners an objective limb load measurement suitable for everyday clinical practice.

\section{METHODS}

This cross-sectional study was conducted with 33 nondisabled adults (15 male, 18 female) recruited through convenience sampling from the physiotherapy department at a public university teaching hospital. Participants with impairments to the lower limb, history of lower-limb surgery, inadequate visual and hearing ability, neuromusculoskeletal impairment, and limb-length discrepancy more than $1 \mathrm{~cm}$ were excluded. Measurements with a DWS were administered in the Department of Physiotherapy, followed by MatScan measurements at the Department of Orthopedics and Traumatology. The study protocol was approved by the university research ethics committee. Prior to data collection, informed consent was obtained from each participant.

Weight distribution between lower limbs was measured by two Beurer DWSs (named hereafter as A and B) (BEU-GS27-007, Beurer GmbH; Ulm, Germany), each with $0.1 \mathrm{~kg}$ precision. The maximum limit of measurement for individual DWSs was $150 \mathrm{~kg}$. Plantar pressure distribution on the lower limbs was measured by MatScan Systems version 6.3. MatScan sensor type was 3150 and was made up of over 2,000 individual pressure-sensing locations, which were referred to as "sensing elements" or "sensels."

\section{Procedures}

\section{Procedure for Digital Weight Scale}

Prior to measurements, calibration of the two DWSs was established by standard test loads [17]. DWSs were placed side by side [18] on a hard, flat surface. The positions of the two DWSs were marked with tape on the floor to ensure the same placement. Participants were asked to stand with bare feet placed centrally on each DWS to ensure even weight distribution on load cells and were instructed to stand with feet placed shoulder-width apart [18] with their hands at their sides [1]. They were instructed to look straight ahead [19] throughout their stance on the DWSs. Participants were allowed to step up on the DWSs with either foot [18]. They then stood in 
their habitual standing posture for $10 \mathrm{~s}$, and then measurements were recorded $[11,20]$. Measurement was done with EO followed by EC conditions. Three trials for EO and EC were conducted and averaged for analysis. Participants were given rest time up to $5 \mathrm{~min}$ as needed between EO and EC trial conditions. The positions of the two DWSs were alternated between trials to minimize possible random error. The calibration of the DWSs was carried out between each trial when the participants stepped off from the DWSs and the display was ensured to read $0 \mathrm{~kg}$ [17]. Each participant spent an average of 20 to 25 min to complete all the trials. Similar procedure was conducted for reliability, validity, and agreement studies.

\section{Procedure for MatScan}

Plantar pressure measurements were obtained from MatScan for individual limbs based on MatScan research software 2009. Mat calibration was done prior to each testing session for each subject using his or her own body weight [20]. Sensitivity of MatScan was set at "high-1" since the "default" sensitivity setting is unable to detect plantar pressure of toes while standing. Six readings of approximately $10 \mathrm{~s}$ (100 frames per reading) for each trial were recorded. Each EO trial was followed by an EC trial. To prevent rater bias, only one researcher collected data throughout the study.

Symmetry index (SI) is a mathematical model that has been widely used to measure loading asymmetry in standing [21]. In this study, LLA was calculated using SI.

The measurements are given in kilograms for the DWS and kilopascals for MatScan. Percentage of weight distribution (PWD) and percentage of pressure distribution (PPD) were calculated from measurements of DWS and MatScan, respectively, based on the adapted SI formula as shown here.

\section{PWD of DWS (Equation 1):}

$$
\left\{\frac{\mathrm{W}_{\max }-\mathrm{W}_{\text {min }}}{\mathrm{W}_{\text {total }}}\right\} \times 100 \%,
$$

where $\mathrm{W}_{\max }$ is the weight of maximum loaded limb (kilograms), $\mathrm{W}_{\min }$ is the weight of minimum loaded limb (kilograms), and $\mathrm{W}_{\text {total }}$ is total weight distribution $\left(\mathrm{W}_{\max }+\right.$ $\left.\mathrm{W}_{\min }\right)$.

PPD of MatScan (Equation 2):

$$
\left\{\frac{\mathrm{PP}_{\text {max }}-\mathrm{PP}_{\min }}{\mathrm{PP} \mathrm{t}_{\text {total }}}\right\} \times 100 \% \text {, }
$$

where $\mathrm{PP}_{\max }$ is the plantar pressure of maximum loaded limb (kilopascals), $\mathrm{PP}_{\min }$ is the plantar pressure of minimum loaded limb (kilopascals), and $\mathrm{PP}_{\text {total }}$ is total pressure distribution $\left(\mathrm{PP}_{\max }+\mathrm{PP}_{\min }\right)$.

\section{Statistical Analysis}

The data were analyzed using SPSS version 20 (IBM Corporation; Armonk, New York). Normality was established using the Shapiro-Wilk test for weight and pressure distribution. To assess intra- and interrater reliability of DWSs A and B during EO and EC, intraclass correlation coefficient (ICC) [1,3] with 95 percent confidence interval was used [22]. ICC value $>0.8$ indicated excellent reliability, 0.4 to 0.8 indicated adequate reliability, and $<0.4$ indicated poor reliability [23]. Bland-Altman plot was employed to measure agreement of LLA values of DWS with MatScan. To construct a Bland-Altman plot, the difference between PWD and PPD was plotted on the $y$-axis against the average of total PWD and PPD on the $x$-axis. There was heteroscedasticity for measurements of PWD and PPD indicated by negative slope of the regression line, and right skewness of data was observed. Hence, square root transformation was used to normalize and reduce the heteroscedasticity in PWD and PPD. Score difference was calculated within the 95 percent limits of agreement (LoAs). Systematic error in terms of bias and random error in terms of precision were calculated to determine the agreement between DWS and MatScan [16]. Bias was defined as mean difference obtained with DWS and MatScan [16]. Standard deviation (SD) reflects precision by measuring the variability (repeatability) of individual differences within 95 percent LoAs [16]. Together with SD in reflecting precision, confidence limit was constructed in the range where 95 percent of differences from bias were expected to lie [16]. Percentage error was calculated to measure the proportion between error in measurement and the magnitude of measurement by the following formula: confidence interval (upper limit - lower limit) / mean of MatScan [16]. Bias trend was analyzed to investigate the tendency for the mean difference in measurements to rise or fall with increasing magnitude. Furthermore, a receiver operating characteristic (ROC) curve was employed to examine the validity of DWS in comparison with MatScan. Level of significance was set at 0.05 . 


\section{RESULTS}

Thirty-three (15 males, 18 females) nondisabled volunteers participated in this study, with mean age of $59.24 \pm$ $6.05 \mathrm{yr}$ and mean body mass index of $25.67 \pm 4.89 \mathrm{~kg} / \mathrm{m}^{2}$. The mean and SD of the SI measurements for limb loading were DWS (EO) $4.45 \pm 3.42$, DWS (EC) $5.44 \pm 4.30$, MatScan (EO) $9.02 \pm 6.80$, and MatScan (EC) $8.93 \pm 7.06$.

\section{Intra- and Interrater Reliability of Digital Weight Scales $A$ and $B$}

The ICC values for each of the outcome measure within and between DWSs A and B in static standing in EO and EC conditions are summarized in the Table. The inter- and intrarater reliability values given by ICC demonstrate excellent reliability (0.94-0.97).

\section{Bland-Altman Analysis for Digital Weight Scale and MatScan During Eyes Open Condition}

The mean \pm SD for PWD measurement using DWS was $1.99 \pm 0.88$ percent, compared with $2.70 \pm 1.13$ percent for PPD measurement using MatScan during EO. The LoAs $(-13.96,5.30)$ contained 97 percent $(32 / 33)$ of the difference scores. The bias of the measurements between DWS A and MatScan during EO indicated DWS underestimated 0.51 percent of measurements of MatScan. Precision of DWS against MatScan was 2.28 percent, percentage error was 2.63 percent, and width of the 95 percent LoAs was 19.27 percent. The linear regression line and zero bias line were within 95 percent LoAs (Figure 1).

\section{Bland-Altman Analysis for Digital Weight Scale and MatScan During Eyes Closed Condition}

The mean \pm SD for PWD measurement using DWS was $2.10 \pm 0.90$ percent, compared with $2.70 \pm 1.13$ percent for PPD measurement using MatScan during EC. The LoAs $(-9.76,4.21)$ contained 100 percent $(33 / 33)$ of the difference scores. The bias of the measurements between DWS A and MatScan during EC indicated DWS underestimated 0.29 percent of measurements of MatScan. Precision of DWS against MatScan was 1.67 percent, percentage error was 2.01 percent, and width of the 95 percent LoAs was 13.97 percent. The linear regression line and zero bias line were within 95 percent LoAs (Figure 2).

\section{Analysis of Validity of Digital Weight Scale with MatScan}

ROC curve was used to validate DWS against MatScan. Figure 3 shows the ROC curve for the SI of DWS compared with MatScan. The area under the curve is 0.68 with 95 percent confidence interval. The upper and lower bound values were 0.55 and 0.81 , respectively. The standard error of measurement was 0.07 percent of change between symmetry index of DWS and MatScan. Furthermore, the area under the curve is significantly different from 0.5 since $p$-value is 0.01 .

\section{DISCUSSION}

The aim of the study was to determine reliability of DWS and its validity and agreement against MatScan in limb loading measurement during static standing in EO and EC conditions. The findings show that DWS is a reliable

Table.

Intra- and interrater reliability statistic of digital weight scales (DWSs) A and B in eyes open (EO) and eyes closed (EC) conditions.

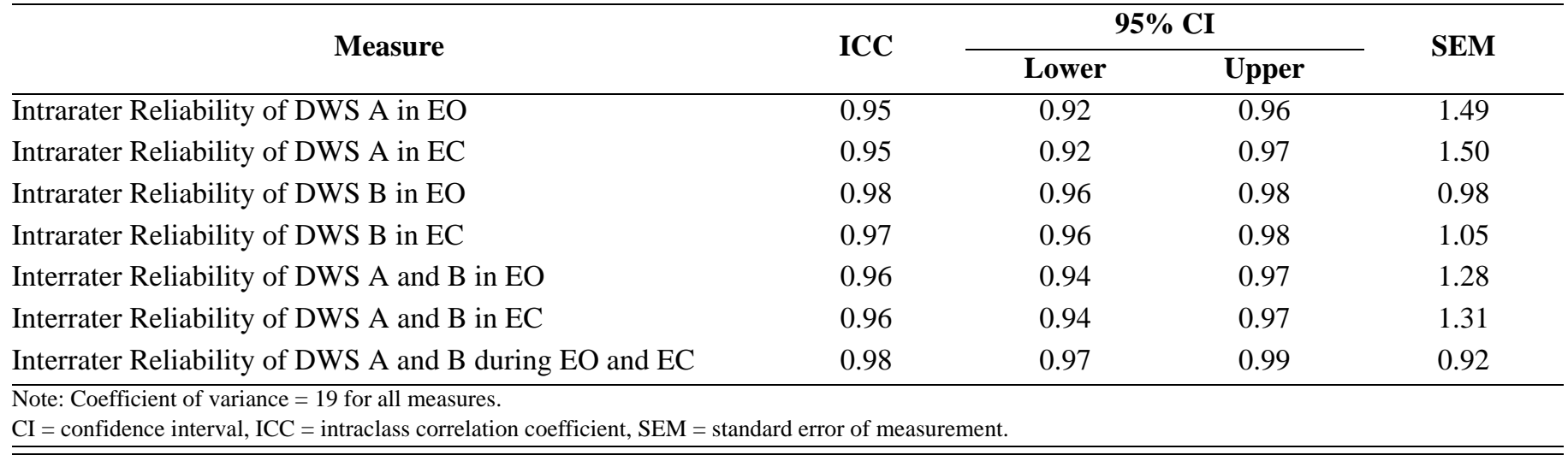


KUMAR et al. Comparing digital weighing scale with MatScan

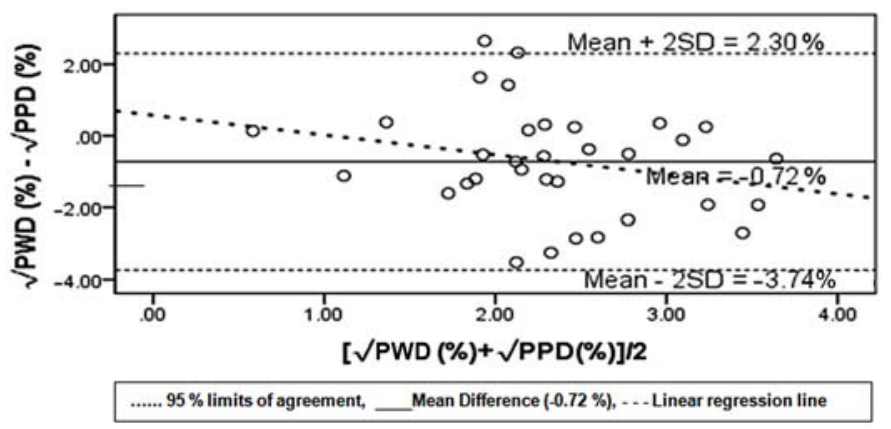

Figure 1.

Bland-Altman plot of digital weight scale (DWS) and MatScan during eyes open condition. PPD = percentage of pressure distribution, PWD = percentage of weight distribution, $\mathrm{SD}=$ standard deviation.

tool, and it establishes good agreement and validity when compared with MatScan. In practice, a force platform is commonly considered the gold standard to measure limb loading in lower limbs [24]. Nevertheless, the validity of MatScan was established to be 1.9 percent of mean difference of measurements compared with force platform [15]. Furthermore, MatScan shows high accuracy with moderate to good reliability in measuring plantar pressure in lower limbs [15].

The reliability within and between DWS A and B was excellent in both EO and EC conditions. The ICC values (0.94-0.97) obtained from repeated limb load measurements of DWS A or DWS B were superior to Bohannon and Waldron's study [25]. Bohannon and Waldron utilized two DWSs and estimated limb load measurement in a stroke population. The ICC was estimated to be 0.83 and 0.88 on the paretic and nonparetic limbs, respectively [25]. The better ICC values obtained in our study could be attributed to the following. To minimize the potential measurement errors, this study exchanged the positions of the two DWSs on every trial. In addition, the sample size (33 subjects) of this study was larger than Bohannon and Waldron's study (20 subjects) [25]. This attribution was made from previous literature, which concludes that averaging the higher number of measurements increases the reliability [26-27]. Hence, to achieve good reliability within and between two DWSs, we propose calibration and alternating position of the two DWS on each trial.

The decision to carry out a Bland-Altman plot was justified because DWS demonstrated high ICC in repeated

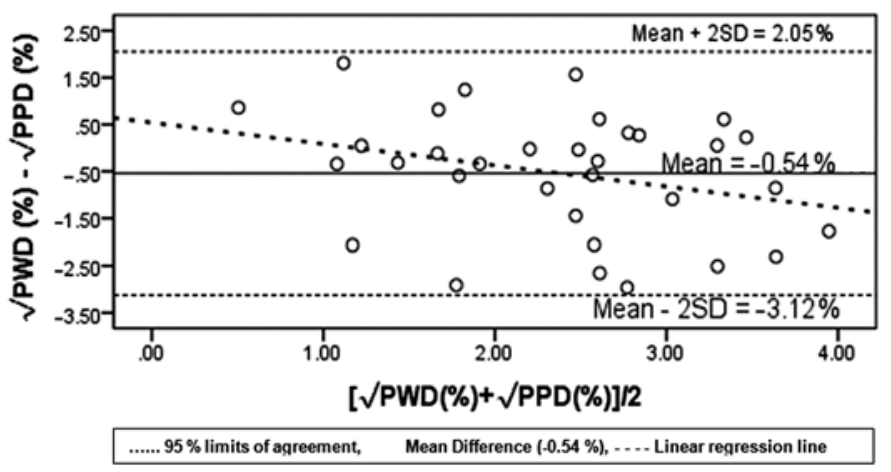

Figure 2.

Bland-Altman plot of digital weight scale (DWS) and MatScan during eyes closed condition. PPD = percentage of pressure distribution, $\mathrm{PWD}=$ percentage of weight distribution, $\mathrm{SD}=$ standard deviation.

measurements [16]. In order to have a good agreement, the LLA measures of DWS should be equal or nearly equal to that of MatScan measurements. Bias represents the measurement differences between the tools, and it should ideally be zero $[16,28]$. Bias estimated between DWS and MatScan in EO and EC conditions differs by 0.51 percent and 0.29 percent, respectively. The bias shows the difference in LLA measures obtained from DWS and MatScan in reference to SI. Considering an individual with body weight $70 \mathrm{~kg}$, this difference in SI would reflect an LLA of 200 and $400 \mathrm{~g}$ in EC and EO conditions. However, there is

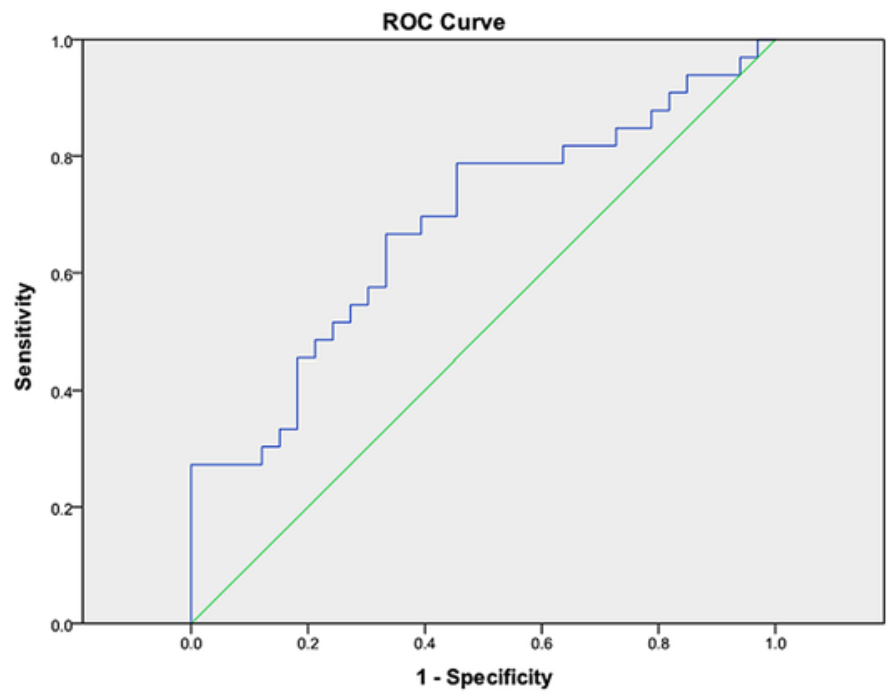

Figure 3.

Receiver operating characteristic (ROC) curve (\%). 
no precise cut-off value established for asymmetrical loading so far in the nondisabled population. The following are the justifications for the small difference in the bias estimated from DWS. The World Health Organization recommends weight be measured to the nearest $0.1 \mathrm{~kg}$ in order to assess nutritional status for an individual [29-30]. Furthermore, in rehabilitation practice, weight measurement using two DWSs was repeated only if more than $1 \mathrm{~kg}$ difference was observed [11,29,31]. Moreover, in clinical practice the DWSs used to measure weight distribution belong to International Organization of Legal Metrology class M 3 and above, where the maximum permissible errors from nominal value at $1 \mathrm{~kg}$ is $\pm 500 \mathrm{mg}$ [32]. Furthermore, the DWSs used in this study has a predefined accredited precision of $0.1 \mathrm{~kg}$ precision. These reasons suggest that the biases of 0.51 percent and 0.29 percent are unlikely to cause concern in clinical diagnosis of LLA [32]. Hence, we believe that this small difference would not change the clinical usage of DWS in addition to its advantages in place of MatScan.

In addition to the bias, Bland-Altman plot can be analyzed further based on plot pattern, precision, percentage error, LoAs, and bias trend. The plot pattern demonstrates the variance of the measurement, and it does not follow funnel, U, or linear patterns. The plots from EO and EC conditions show no relationship between discrepancy and level of measurement, allowing us to conclude that 95 percent LoAs would be appropriate between DWS and MatScan. The precision refers to one SD that describes the range for 68 percent of comparison points. Precision was \pm 2.28 percent and \pm 1.67 percent, with the percentage error of 2.63 percent and 2.01 percent for EO and EC conditions, respectively. To the best of our knowledge, there is no established standard set value for precision and percentage error for these two pieces of equipment. However, the smaller precision error indicates that the data points are closer to the mean, representing a better agreement [33-34]. LoAs refers to mean difference plus or minus two SD that describes the range for 95 percent of comparison points. LoA described the variance around the bias with EO $(-13.96,5.30)$ and EC $(-9.76,4.21)$. From a literature search, we concluded that the agreement of DWS and MatScan based on LoA is a clinical, not a statistical, decision [35]. Despite this, the LoAs are small enough for us to be confident that the DWS can be used in place of MatScan for clinical measurement of limb loading. The regression line and the zero bias line in both EO and EC conditions fell within the 95 percent confidence interval band; hence, we can conclude that the bias trend is not statistically different from the zero bias line, representing good agreement between DWS and MatScan. All these findings suggest that DWS could be a good substitute for MatScan in limb load measurement during EO and EC.

In respect to validity, the area under the ROC curve ranges from 0.5 and 1.0, with a larger value close to 1 indicating a better fit between equipment [36-37]. The area under the ROC curve was identified as 0.68 , which is considered to be a good fit because it falls between 0.5 and 1.0. The $p$-value from the ROC curve is significant $(p=$ 0.01 ) and the lower bound value is 0.55 , which is greater than 0.5 . In addition, the logistic regression line classifies that the significant results are not by chance.

Overall, repeated measures within and between DWSs A and B showed excellent reliability in addition to good agreement and valid limb LLA measures against MatScan in EO and EC conditions. Hence, DWSs can be incorporated by practitioners as advantageous equipment to evaluate LLA during standing. DWSs are compact, portable, economic, and easily available [38]. DWSs could deputize subjective clinical examination and objectively evaluate the limb loading in clinical practice.

\section{CONCLUSIONS}

DWSs have excellent reliability in static limb loading measurement. Similarly, measurements of DWSs were in good agreement and held validity with measurements of MatScan during EO and EC conditions. Hence, DWSs may be utilized for evaluation of LLA in clinical settings.

\section{ACKNOWLEDGMENTS}

\section{Author Contributions:}

Study concept and design: L. H. Joseph, B. Omar, S. N. S. Kumar. Acquisition of data: L. L. Min, S. N. S. Kumar.

Analysis and interpretation of data: L. H. Joseph, B. Omar, S. N. S. Kumar, L. L. Min, J. Krishnan, A. Jafarzedah Esfehani, O. Htwe.

Drafting of manuscript: L. H. Joseph, B. Omar, S. N. S. Kumar, L. L. Min.

Critical revision of manuscript for important intellectual content: L. H. Joseph, B. Omar, S. N. S. Kumar, L. L. Min, J. Krishnan, A. Jafarzedah Esfehani, O. Htwe.

Study supervision: L. H. Joseph, B. Omar, S. N. S. Kumar, J. Krishnan, O. Htwe. 
Final approval for manuscript to be published: L. H. Joseph, B. Omar, S. N. S. Kumar, L. L. Min, J. Krishnan, A. Jafarzedah Esfehani, O. Htwe. Financial Disclosures: The authors have declared that no competing interests exist.

Funding/Support: This material was based on work supported by eScienceFund (grant 06-01-02-SF1035).

Additional Contributions: We would like to thank the staff of the Department of Physiotherapy for helping during this project. We would also like to thank all participants for their willingness to be involved in this study.

Institutional Review: This study was approved by Research Ethics Committee of The National University of Malaysia with Reference No. UKM1.21.3/244/ on April 23, 2012. All participants were informed about the aims of the study. Informed consent was obtained from all participants. Results were disclosed to all participants in this study.

Participant Follow-Up: The authors have no plans to notify the study subjects of the publication of this article because of a lack of contact information.

Disclaimer: All the authors take the responsibility in ensuring the integrity of this manuscript as a whole, from inception to finished manuscript.

\section{REFERENCES}

1. Talis VL, Grishin AA, Solopova IA, Oskanyan TL, Belenky VE, Ivanenko YP. Asymmetric leg loading during sit-to-stand, walking and quiet standing in patients after unilateral total hip replacement surgery. Clin Biomech (Bristol, Avon). 2008;23(4):424-33. [PMID:18164792] http://dx.doi.org/10.1016/j.clinbiomech.2007.11.010

2. Harato K, Otani T, Nakayama N, Watarai H, Wada M, Yoshimine F. When does postoperative standing function after total knee arthroplasty improve beyond preoperative level of function? Knee. 2009;16(2):112-15. [PMID:19036590] http://dx.doi.org/10.1016/j.knee.2008.10.008

3. Blaszczyk JW, Prince F, Raiche M, Hébert R. Effect of ageing and vision on limb load asymmetry during quiet stance. J Biomech. 2000;33(10):1243-48. [PMID:10899333] http://dx.doi.org/10.1016/S0021-9290(00)00097-X

4. Redfern MS, Yardley L, Bronstein AM. Visual influences on balance. J Anxiety Disord. 2001;15(1-2):81-94. [PMID:11388359] http://dx.doi.org/10.1016/S0887-6185(00)00043-8

5 . Bauer K. The difference on weight bearing asymmetry in the frontal plane by treating the upper cervical spine with HVLA-thrust or strain/counterstrain [Dissertation]. [Berlin, Germany]: Wiener Schule für Osteopathie and Donau Universität Krems; 2009.

6. Hurkmans HL, Bussmann JB, Benda E, Verhaar JA, Stam HJ. Techniques for measuring weight bearing during standing and walking. Clin Biomech (Bristol, Avon). 2003; 18(7):576-89. [PMID:12880705] http://dx.doi.org/10.1016/S0268-0033(03)00116-5
7. Halanski M, Noonan KJ. Cast and splint immobilization: Complications. J Am Acad Orthop Surg. 2008;16(1):30-40. [PMID:18180390]

8. Hudson TS, Forman MR, Cantwell MM, Schatzkin A, Albert PS, Lanza E. Dietary fiber intake: Assessing the degree of agreement between food frequency questionnaires and 4-day food records. J Am Coll Nutr. 2006;25(5): 370-81. [PMID:17031005] http://dx.doi.org/10.1080/07315724.2006.10719548

9. Isakov E. Gait rehabilitation: A new biofeedback device for monitoring and enhancing weight-bearing over the affected lower limb. Eura Medicophys. 2007;43(1):21-26. [PMID:17021589]

10. Genthon N, Gissot A-S, Froger J, Rougier P, Pérennou D. Posturography in patients with stroke: Estimating the percentage of body weight on each foot from a single force platform. Stroke. 2008;39(2):489. [PMID:18174486] http://dx.doi.org/10.1161/STROKEAHA.107.493478

11. Pereira LC, Botelho AC, Martins EF. Relationships between body symmetry during weight-bearing and functional reach among chronic hemiparetic patients. Revista Brasileira de Fisioterapia. 2010;14(3):229-66. [PMID:20730367]

12. Laufer Y, Dickstein R, Resnik S, Marcovitz E. Weightbearing shifts of hemiparetic and healthy adults upon stepping on stairs of various heights. Clin Rehabil. 2000;14(2): 125-29. [PMID:10763788] http://dx.doi.org/10.1191/026921500674231381

13. Atkinson G, Nevill AM. Statistical methods for assessing measurement error (reliability) in variables relevant to sports medicine. Sports Med. 1998;26(4):217-38. [PMID:9820922] http://dx.doi.org/10.2165/00007256-199826040-00002

14. Kottner J, Audigé L, Brorson S, Donner A, Gajewski BJ, Hróbjartsson A, Roberts C, Shoukri M, Streiner DL. Guidelines for reporting reliability and agreement studies (GRRAS) were proposed. Int J Nurs Stud. 2011;48(6):661-71.

[PMID:21514934]

http://dx.doi.org/10.1016/j.ijnurstu.2011.01.016

15. Zammit GV, Menz HB, Munteanu SE. Research reliability of the TekScan MatScan ${ }^{\circledR}$ system for the measurement of plantar forces and pressures during barefoot level walking in healthy adults. J Foot Ankle Res. 2010;3:11.

[PMID:20565812]

http://dx.doi.org/10.1186/1757-1146-3-11

16. Hanneman SK. Design, analysis, and interpretation of method-comparison studies. AACN Adv Crit Care. 2008; 19(2):223-34. [PMID:18560291] http://dx.doi.org/10.1097/01.AACN.0000318125.41512.a3

17. Adegoke BO, Olaniyi O, Akosile CO. Weight bearing asymmetry and functional ambulation performance in stroke survivors. Global Journal of Health Science. 2012; 4(2):87-94. [PMID:22980155] http://dx.doi.org/10.5539/gjhs.v4n2p87 
18. Childs JD, Piva SR, Erhard RE, Hicks G. Side-to-side weight-bearing asymmetry in subjects with low back pain. Man Ther. 2003;8(3):166-69. [PMID:12909437] http://dx.doi.org/10.1016/S1356-689X(03)00014-6

19. Skjæret N. Weight-bearing characteristics during standing in adults with cerebral palsy [Thesis]. [Trondheim, Norway]: Norwegian University of Science and Technology; 2011.

20. Grassi DO, de Souza MZ, Ferrareto SB, Montebelo MI, Guirro EC. Immediate and lasting improvements in weight distribution seen in baropodometry following a high-velocity, low-amplitude thrust manipulation of the sacroiliac joint. Man Ther. 2011;16(5):495-500. [PMID:21570892] http://dx.doi.org/10.1016/j.math.2011.04.003

21. Robinson RO, Herzog W, Nigg BM. Use of force platform variables to quantify the effects of chiropractic manipulation on gait symmetry. J Manipulative Physiol Ther. 1987; 10(4):172-76. [PMID:2958572]

22. Bruton A, Conway JH, Holgate ST. Reliability: What is it, and how is it measured? Physiotherapy. 2000;86(2):94-99. http://dx.doi.org/10.1016/S0031-9406(05)61211-4

23. Pollock C, Eng J, Garland S. Clinical measurement of walking balance in people post stroke: A systematic review. Clin Rehabil. 2011;25(8):693-708. [PMID:21613511] http://dx.doi.org/10.1177/0269215510397394

24. Walsh M, Ford K, Bangen K, Myer G, Hewitt T. Validation of a portable force plate to assessing jumping and landing performance. Proceedings of the 23rd International Symposium on Biomechanics in Sports; 2008 Aug 22-27. Beijing, China.

25. Bohannon R, Waldron R. Weightbearing during comfortable stance in patients with stroke: Accuracy and reliability of measurements. Aust J Physiother. 1991;37:19-22. http://dx.doi.org/10.1016/S0004-9514(14)60530-4

26. Henry F. “Best” versus “average” individual scores. Res Q. 1967;38:317-20.

27. Button KS, Ioannidis JP, Mokrysz C, Nosek BA, Flint J, Robinson ES, Munafò MR. Power failure: Why small sample size undermines the reliability of neuroscience. Nat Rev Neurosci. 2013;14(5):365-76. [PMID:23571845] http://dx.doi.org/10.1038/nrn3475

28. Bland JM, Altman DG. Comparing methods of measurement: Why plotting difference against standard method is misleading. Lancet. 1995;346(8982):1085-87. [PMID:7564793] http://dx.doi.org/10.1016/S0140-6736(95)91748-9

29. Kirogo V, Kogi-Makau W, Muroki NM. The role of irrigation on improvement of nutritionalstatus of young children in Central Kenya. Aftican J Food Agriculture Nutrition Dev. 2007;7(2).

30. Lavaipierre G, Lavoipierre G. Measuring change in nutritional status: Guidelines for assessing the nutritional impact of supplementary feeding programmes for vulnerable groups. Geneva (Switzerland): World Health Organization; 1983.
31. Euser AM. Long-term consequences of differences in early growth: epidemiological aspects [Dissertation]. [Leiden, the Netherlands]: Leiden University; 2009.

32. Service UK. Calibration of weighing machines. In: Service A. 4th ed. United Kingdom: UKAS publications; 2006. p. 2-3.

33. Chiari L, Rocchi L, Cappello A. Stabilometric parameters are affected by anthropometry and foot placement. Clin Biomech (Bristol, Avon). 2002;17(9-10):666-77. [PMID:12446163] http://dx.doi.org/10.1016/S0268-0033(02)00107-9

34. Cecconi M, Rhodes A, Poloniecki J, Della Rocca G, Grounds RM. Bench-to-bedside review: The importance of the precision of the reference technique in method comparison studies - with specific reference to the measurement of cardiac output. Crit Care. 2009;13(1):201. [PMID:19183431] http://dx.doi.org/10.1186/cc7129

35. Bland JM, Altman DG. Applying the right statistics: Analyses of measurement studies. Ultrasound Obstet Gynecol. 2003;22(1):85-93. [PMID:12858311]

http://dx.doi.org/10.1002/uog.122

36. Metz CE. Receiver operating characteristic analysis: A tool for the quantitative evaluation of observer performance and imaging systems. J Am Coll Radiol. 2006;3(6):413-22. [PMID:17412096] http://dx.doi.org/10.1016/j.jacr.2006.02.021

37. McClish DK. Analyzing a portion of the ROC curve. Med Decis Making. 1989;9(3):190-95. [PMID:2668680] http://dx.doi.org/10.1177/0272989X8900900307

38. Sutton P, Stedman J, Livesley P. Perception and education of unilateral weightbearing amongst health care professionals. Injury. 2007;38(2):163-64. [PMID:16979640] http://dx.doi.org/10.1016/j.injury.2006.06.013

Submitted for publication July 22, 2013. Accepted in revised form December 16, 2013.

This article and any supplementary material should be cited as follows:

Kumar SN, Omar B, Htwe O, Joseph LH, Krishnan J, Jafarzedah Esfehani A, Min LL. Reliability, agreement, and validity of digital weighing scale with MatScan in limb load measurement. J Rehabil Res Dev. 2014;51(4): 591-98. http://dx.doi.org/10.1682/JRRD.2013.07.0166

ResearcherID/ORCID: Leonard H. Joseph, MsPT: E-93452014; Senthil N. S. Kumar, MSc: E-9340-2014

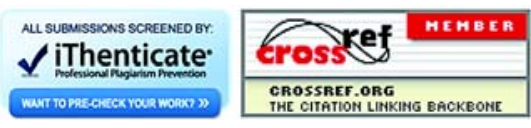

